\title{
Effect of supplementation with vitamin D and calcium to excessive suppression of bone metabolism during antiresorptive therapy
}

Tijana Icin ${ }^{1}$, Branka Kovacev-Zavisic ${ }^{1}$, Jovanka Novakovic-Paro ${ }^{1}$, Ivana Bajkin ${ }^{1}$, Bojan Vukovic ${ }^{2}$, Ivanka Percic ${ }^{2}$, Nemanja Kovacev ${ }^{3}$, Milica Medic-Stojanoska ${ }^{1}$

1 Clinic for endocrinology, diabetes and metabolic diseases, Clinical Center of Vojvodina, Medical faculty, University of Novi Sad, Serbia 2 Emergency Center, Clinical Center of Vojvodina, Medical faculty, University of Novi Sad, Serbia

3 Clinic of Orthopaedic surgery and Traumatology, Clinical Center of Vojvodina, Novi Sad, Serbia

\section{OBJECTIVES}

Long-term therapy with bisphosphonates is considered a risk factor for the development of atypical fractures of the femur. One of the mechanisms of these fractures is excessive suppression of bone metabolism. The supplementation dose of vitamin $\mathrm{D}$ and calcium could have an impact on the degree of suppression of bone turnover.

The aim was to determine whether the presence or dose of supplementation with vitamin $\mathrm{D}$ and calcium during antiresorptive therapy have an impact on the achieved degree of suppression of bone metabolism.

\section{METHODS}

This was a prospective longitudinal study that included 200 postmenopausal women with antiresorptive treatment of osteoporosis. We analyzed osteocalcin, CTx and ionic calcium, before treatment and three months after starting the antiresorptive therapy, and dose of supplementation with vitamin D and calcium during the therapy. Based on the values of osteocalcin and CTx after three months of therapy, patients were divided into four groups:

Group 1 -accelerated bone metabolism

Group 2 -awaited response to therapy

Group 3 -excessive suppression of bone resorption (low CTx)

Group 4 -excessive suppression of bone remodeling (low CTX and low osteocalcin)
Calcium and vitamin D suplementation distribution among the groups

\begin{tabular}{|c|c|c|c|c|c|c|}
\hline $\mathrm{N}=200$ & \multicolumn{2}{|c|}{ No Calcium } & \multicolumn{2}{c|}{ Calcium 500mg/day } & \multicolumn{2}{c|}{ Calcium $1000 \mathrm{mg} /$ day } \\
\hline & $\mathrm{n}$ & $\%$ & $\mathrm{n}$ & $\%$ & $\mathrm{n}$ & $\%$ \\
\hline Group1 & 2. & 10.5 & 13. & 68.4 & 4. & 21.1 \\
\hline Group 2 & 15. & 20.3 & 50. & 67.6 & 9. & 12.2 \\
\hline Group 3 & 23. & 26.1 & 51. & 58.0 & 14. & 15.9 \\
\hline Group 4 & 5. & 26.3 & 13. & 68.4 & 1. & 5.3 \\
\hline
\end{tabular}

$p<0.1 \quad p<0.05$

\begin{tabular}{|l|c|c|c|c|c|c|c|c|}
\hline \multirow{2}{*}{$\mathrm{N}=200$} & \multicolumn{3}{|c|}{ No Vitamin D } & \multicolumn{2}{|c|}{ Vitamin D 400 IU/day } & \multicolumn{2}{|c|}{ Vitamin D 800 IU/day } & \multicolumn{2}{|c|}{$\begin{array}{c}\text { Vitamin D } \geq 1200 \\
\text { IU/day }\end{array}$} \\
\hline & $\mathrm{n}$ & $\%$ & $\mathrm{n}$ & $\%$ & $\mathrm{n}$ & $\%$ & $\mathrm{n}$ & $\%$ \\
\hline Group 1 & 1. & 5.3 & 9. & 47.4 & 9. & 47.4 & 0. & .0 \\
\hline Group2 & 3. & 4.1 & 34. & 45.9 & 27. & 36.5 & 10. & 13.6 \\
\hline Group3 & 10. & $11.4^{*}$ & 47. & 53.4 & 27. & 30.7 & 4. & 4.5 \\
\hline Group5 & 1. & 5.3 & 10. & 52.6 & 7. & 36.8 & 1. & 5.3 \\
\hline
\end{tabular}

\section{RESULTS}

Calcium suplementation was carried out in $77.5 \%$ of patients, usually in a dose of $500 \mathrm{mg}$ per day and vitamin D in $92.5 \%$ usually at a dose of $400 \mathrm{IU}$. The dose of calcium is satisfied recommended dose in $14 \%$ of cases, a dose of vitamin $\mathrm{D}$ in $42.5 \%$ of cases. Calcium supplementation was not associated with the degree of suppression of bone metabolism $(\mathrm{p}=0.557$, $\chi=0.155$ ). Supplementation with vitamin $\mathrm{D}$ was not associated with the degree of suppression of bone metabolism $(\mathrm{p}=0.652, \chi=0.241)$. The values of ionic calcium before and during treatment were in the reference range.

\section{CONCLUSIONS}

Most patients with antiresorptive therapy for osteoporosis takes supplementation with vitamin D and calcium. The supplementation dose in many cases was less than the recommended dose. The degree of suppression of bone metabolism during antiresorptive therapy did not depend on the supplementation dose of calcium nor vitamin D.

\section{REFERENCES:}

Allen M. R, Burr D. B. Bisphosphonate effects on bone turnover, microdamage, and mechanical properties: What we think we know and what we know that we don't know. Bone 2011; 49: 56-65

Clarita V. Odvina, Joseph E. Zerwekh, D. Sudhaker Rao, Naim Maalouf, Frank A. Gottschalk, Charles Y. C. Pak. Severely Suppressed Bone Turnover: A Potential Complication of Alendronate Therapy. The Journal of Clinical Endocrinology \& Metabolism 2005; 90(3):1294 -1301 .

Andrea Giusti, Neveen A.T. Hamdy, Socrates E. Papapoulos. Atypical fractures of the femur and bisphosphonate therapy A systematic review of case/case series studies. Bone 2010; 47: 169-180. 